\title{
Home devices deliver data for dementia care
}

One of the quotes in this article by Fran Robinson (BMJ 2018;361:k1855, doi:10.1136/bmj.k1855) was misattributed to Ramin Nilforooshan rather than Helen Rostill. The fourth paragraph in the section on early results should read: "The study has not been without teething issues; initially some of the devices triggered false alerts. The trust was able to work with the technology companies to correct these technical problems. 'We were concerned at the beginning that people may find the devices and remote monitoring intrusive, but that has not been the case,' says Helen Rostill, director of innovation and development at the trust. 'While most of the devices we have been using are passive and do not require active interaction, we may look in the future at using even less interactive devices to make the system even easier to use for someone with more advanced dementia."” 